\title{
FIRST YEAR STUDENTS' BOREDOM IN AN APPLIED \\ COMMUNICATION SKILLS CLASSROOM AT A SOUTH \\ AFRICAN UNIVERSITY OF TECHNOLOGY
}

\author{
M. R. Erasmus* \\ e-mail: rynette@vut.ac.za
}

\author{
I. Hall* \\ e-mail: ilizmah@vut.ac.za \\ Department of Communication \\ Vaal University of Technology \\ Vanderbijlpark, South Africa
}

\section{ABSTRACT}

Researchers worldwide have reported on student boredom in schools as well as in higher education contexts. However, little attention has been paid to this aspect of student response in South Africa's classrooms. This quantitative study aimed to determine the boredom levels of a group of first-year students at a South African university of technology in the early stages of a compulsory year-long first-year Applied Communication Skills programme conducted in English, and to investigate possible factors associated with boredom. A closed-ended questionnaire was administered to a random sample of 182 students. Unexpectedly, the results revealed lower levels of boredom in class than had been found in earlier international studies. The male students reported less boredom than the female students, and all the students reported significantly less boredom at tertiary level than they had experienced in secondary school. There was no statistically significant correlation between the students' boredom levels and their home language, or between their boredom levels and their self-reported levels of proficiency in English. Although our study focused just on one subject in a single institution, it suggests that student boredom in South Africa may be less prevalent at tertiary level than previously assumed. Future research could usefully investigate levels of student boredom, and associated factors, across a wider range of classes and higher education institutions.

Keywords: boredom, classroom, first-year students, University of Technology (UoT), Applied Communication Skills

\section{INTRODUCTION}

International studies have reported ubiquitous boredom among students at academic institutions. Much has been written internationally about boredom, but little research has been done in the African context on the levels of boredom in the classroom at tertiary level. Some 
studies, however referred to boredom as an aspect which contributed to social anomalies such as substance abuse and school dropout (Weybright et al. 2015). No studies on the level of boredom were done at universities of technology in Africa and more specifically, in South Africa.

This study was conducted to establish the extent of boredom experienced in the first-year University of Technology (UoT) classroom and to investigate possible contributory factors. The diversity of the student population at this UoT, necessitated this study, which might contribute to the lack of research done in the African context.

Boredom has been investigated by researchers worldwide, as seen in the following studies: Eastwood et al. $(2012,482)$ stated that it was found in previous international research that boredom is associated with a range of psychological, social and physical health problems such as depression, anxiety, gambling, drug use and delinquency (as in Amos et al. 2006; Goldberg et al. 2011). Eastwood furthermore stated that the purpose in life may be undesirably influenced by boredom (as in Melton and Schulenberg 2007; Fahlman et al. 2009; Van Tilburg and Igou 2011).

Pekrun et al. $(2014,696)$ stated that boredom has been described as an emotion that is among the most frequently experienced, and potentially most devastating, affective states occurring in the classroom (as in Mann and Robinson 2009; Pekrun et al. 2010). An individual who is bored has difficulty concentrating and paying attention, both of which conditions are associated with diminished learning. Boredom reduces effective learning and effort is required to maintain focus on (rather than becoming distracted from) what is going on in the environment (Macklem 2015, 1-2).

According to Pekrun et al. $(2010,531)$ researchers have given more attention to emotions such as anxiety, anger, joy or interest than to boredom; maybe because boredom is regarded as a "silent" emotion as compared with affective states such as anger or anxiety which are displayed more openly. As boredom is one of the most commonly experienced emotions in everyday life, it has been generalized that students are bored during classes at academic institutions (Tze et al. 2013, 32).

The literature records many different definitions of boredom (Vogel-Walcutt et al. 2012). Greenson (1953), an early researcher in this field, described boredom as an experience associated with an inability to specify what one desires, a passive attitude hoping for a change from an external source, and a sense of time distortion. O'Hanlon $(1981,76)$ proposed that boredom be viewed as a "unique psychophysiological state that comprises a set of interrelated emotional, motivational and cognitive reactions having a common biological basis".

Furthermore, boredom has been identified as a distinct emotional state (Farmer and 
Sundberg 1986; Fisher 1993) and, according to Fisher, it is "an unpleasant, transient affective state in which the individual feels a pervasive lack of interest in and difficulty concentrating on the current activity ... [such that] it takes conscious effort to maintain or return attention to that activity" (Fisher 1993, 396). Geiwitz $(1996,598)$ concluded that boredom was related to "low arousal, increased feelings of unpleasantness, constraint and repetitiveness".

According to Fallis and Opotow $(2003,108)$, boredom connotes something missing in students' education, conveys a deep sense of disappointment, and sees absence from class as a way of coping with classes that insufficiently engage the student cognitively. More recently, Eastwood et al. (2012) remarked that boredom is a negative emotion whereby one cannot meaningfully engage in a task, is unable to sustain required attention, and allocates the blame to an external environment. For Van Tilburg and Igou (2012), boredom comprises "unpleasant feelings, reduced physiological arousal, perceived lack of cognitive stimulation, task-irrelevant thinking or daydreaming, prolonged subjective duration of time, and impulses to escape the boredom-inducing situation through disengagement". As boredom is one of the most commonly experienced emotions in everyday life, it has been generalized that students are bored during classes at academic institutions (Tze et al. 2013, 32).

Contrary to popular perception, boredom is not the result of having nothing to do; rather, it stems from a situation where none of the possible things that a person can realistically do appeal to the person in question (Mann and Robinson 2009). Previous research has identified large numbers of variables that influence student boredom in the classroom. Tze et al. (2013) stated that among the symptoms, students appear to be lethargic, irritated, apathetic, disengaged, uninvolved, listless, restless, uninterested, fiddling with cell phones and not concentrating (as in Pekrun et al. 2010; Wegner et al. 2008).

In spite of general interest in the topic over the past decades, Mann and Robinson (2009, 247) have criticized research into classroom boredom for concentrating mostly on boredom among school-age children. However, the question remains as to what factors contribute to student boredom in the classroom (Mann and Robinson 2009). Studies where the levels of boredom as a result of the learning content, and teaching methods experienced in the tertiary classroom, could not be identified in the SA context. The studies which have been done in SA, focused on boredom as a possible factor impacting on aspects such as academic performance (Fraser and Killen 2005).

This study focused more pertinently on the levels of boredom in the classroom at this UoT where students in compulsory first-year lectures appeared to be bored and not paying attention. Students seemed aloof and frequently cut classes. As teaching excellence is a priority at the institution in the study, it was regarded as important for lecturers to implement teaching 
methods and learning material with which students could engage, as a way to minimize student boredom.

It is also important to take into account how boredom affected the pedagogical process. According to the UNESCO learning portal $(2018,1)$ pedagogy refers to the "interactions between teachers, students, and the learning environment and the learning tasks". Effective pedagogy can lead to academic achievement, social and emotional development, acquisition of technical skills and the general ability to contribute to society.

Boredom affects the pedagogical learning process in that learners who are bored, are not able to focus and engage in the learning process. According to Mann and Robinson $(2009,247)$, Ward (2003) observed first-hand the coping strategies that students used to combat boredom: Some dozed off and daydreamed or doodled in time-dishonored fashion; others took refuge in their mobile phones sending or reading text messages, or playing games. Ward (2003) furthermore stated that in the corner in which he regularly sat, there were competitions of hangman, complete the song lyric, and quizzes of one sort or another. It was not long before this kind of subversion became more obvious as students started to skip classes. There were times when attendance slumped to 50 per cent. Some students even disappeared in the midsession break, deciding that it wasn't worth staying and electing to do something else instead.

Thus, it is evident from these examples that boredom plays an important role in the pedagogical learning process. This is supported by Mann and Robinson, $(2009,248)$ in their statement that boredom at tertiary level might have serious consequences for students in terms of their academic achievement. In order to prevent the negative effects of boredom, practitioners need to implement a variety of strategies to capture the attention of those students who show symptoms of possible boredom.

The student population selected for our study comprised UoT students who had been brought up in any one of twelve home languages and who came from a variety of different geographical and cultural backgrounds. The medium of instruction and the language spoken by students in South Africa is mainly English, for most of whom it is a second language rather than a home language. Our research focused on student boredom in the Applied Communication Skills first-year classroom. It is presented as a compulsory service subject offered to students enrolled for a variety of courses from all the faculties at this UoT. The class sizes ranged from 20 to 60 students.

The purpose of the present study was to investigate whether or not our sample of UoT students at the South African tertiary level were in fact bored and, if so, what might be among the contributory causes. 


\section{THEORETICAL BACKGROUND}

This study is underpinned by several theoretical studies. In 1903, some of the initial psychodynamic theories were envisaged by Lipps: "Boredom is a feeling of unpleasure arising out of a conflict between a need for intense mental activity and lack of incitement to it, or inability to be incited" (Lipps 1903). Sigmund Freud (writing between the 1890s and the 1930s) developed a collection of theories which have formed the basis of the psychodynamic approach to psychology. Secondly, most existential definitions of boredom which see the individual as having freedom of choice and is responsible for this choice, define the bored individual as withdrawing himself/herself from the world, being unable to find motivation to act, and experiencing life as worthless. Feelings of desolation, purposelessness and inaction may be experienced (e.g. Frankl 1984; Maddi 1970).

Thirdly, according to the Arousal theories, boredom can be seen as resulting from a discrepancy between a lack of environmental stimulation and the individual's need for arousal. More specifically, the environment may present too much or too little challenge and thus does not afford satisfying activity (Berlyne 1960; Hebb 1966; O’Hanlon 1981). This theory has been superseded by The Yerkes-Dodson law which is an empirical relationship between arousal and performance developed by psychologists Robert M. Yerkes and John Dillingham Dodson in 1908. These theories imply that boredom is an undesirable state which happens when the individual is unable to engage optimally with the environment.

In contrast with the arousal theories which emphasize the importance of the stimulating milieu, cognitive theories of boredom focus on individual perceptions of the milieu as uninteresting (Hamilton, Haier and Buchsbaum 1984; Hill and Perkins, 1985). They emphasize the fact that bored individuals may experience a lack of concentration and may find it exerting to be attentive. (Fisher 1993; Hamilton 1981; Harris 2000; Todman 2003). Thus, the definition of boredom from the cognitive perspective emphasizes both the attribution to an environment that lacks opportunities to satisfy activity, and to the individual's weakened skill to focus.

Although the psychodynamic, existential, arousal, and cognitive theories differ in important ways, they agree that, by definition, the bored person wishes to, but is unable to, become absorbed in fulfilling activity. According to Eastwood et al. $(2012,484)$, boredom is the experience of being detached and trapped in an endless desolated inactive present.

The Constructivism Theory as founded by Piaget (as in David 2018) underpins our study. Piaget's theory of constructivism addresses how learning actually occurs. It is stated that the role of teachers is very important. Instead of giving a lecture the teachers in this theory function as facilitators whose role is to aid the student when it comes to their own understanding. The resources and lesson plans that must be initiated for this learning theory take a very different 
approach toward traditional learning as well. Teachers following Piaget's theory of constructivism must challenge the student by making them effective critical thinkers and not being merely a "teacher" but also a mentor, a consultant, and a coach.

\section{METHODOLOGY}

This article aims to firstly investigate which factors were involved in the construct of boredom by providing statements on a 5-point interval scale by using factor analysis. Secondly, the factors obtained were used as the dependent variables and measured their possible association with the independent variables in the questionnaire. The findings were used to provide possible solutions to feelings of perceived boredom as a means to improve subject content and teaching methods.

\section{Research design}

A quantitative research method was used for this empirical study. Our goal in conducting quantitative research study was to determine the relationship between the independent variables (bio-graphic and demographic) and the dependent variables (subject content and teaching methods) within a population. This study was descriptive because it established only associations between variables.

The overarching aim of a quantitative research study is to classify features, count them, and construct statistical models in an attempt to explain what is observed (http://libguides.usc. edu/writingguide/quantitative).

\section{Participants}

The population consisted of first-year UoT students enrolled for Applied Communication Skills. Simple random sampling was used. The students involved represented all the faculties of VUT, namely Human Sciences; Applied and Computer Sciences; Management Sciences; and Engineering and Technology. The initial sample size consisted of 200 questionnaires but only 182 were submitted. Three questionnaires of the 182 were discarded because they were incomplete leaving us with 179.

\section{Information gathering}

In educational planning standardized questionnaires are often used to collect information about various aspects of school systems (Siniscalco and Auriat 2005). Information was collected by independent personnel of the English Development Laboratories through self-administered structured questionnaires, given to 200 first-year Applied Communication students at a UoT. 


\section{Instruments}

Although various tools are used to measure boredom, such as the Boredom Coping Scale (Eastwood 2013) and the Boredom Propensity Scale (Farmer and Sundberg 1986), none of these were used in this study, as they focus on specific effects of boredom such as emotion, depression and thrill-seeking behaviours, rather than on factors such as learning content and teaching methodology which were more relevant to our study.

Data was collected through a structured questionnaire, which was administered to 200 first-year students enrolled for Applied Communication Skills, in the university's English Development Laboratories, over a period of three weeks. The questionnaire consisted of three sections - Section A: Demographic information; Section B: Boredom at secondary school; and Section C: Boredom at tertiary educational level. Sections B and C comprised 39 and 44 5-point Likert scale questions, respectively, ranging from "strongly disagree" to "strongly agree", which enabled students to indicate the extent to which the statements applied to them, as shown in Table 1. The questions did not focus on boredom in the applied communication skills course, but on boredom experienced in general in the classroom, at these levels.

Table 1: Example of a 5-point Likert scale question in the questionnaire

\begin{tabular}{|c|c|c|c|c|c|}
\hline \multicolumn{6}{|c|}{$\begin{array}{l}\text { SECTION B: BOREDOM AT SECONDARY SCHOOL } \\
\text { Bored - feeling tired and impatient because you have lost interest in something or because you have } \\
\text { nothing to do. } \\
\text { Biased - influence in an unfair way; prevents objective consideration of an issue/situation. } \\
\text { Circle the correct numeric response to each question }\end{array}$} \\
\hline \multicolumn{6}{|c|}{ Survey scale: 1 = Strongly disagree; 2 = Disagree; 3 = Neutral; 4 = Agree; 5 = Strongly agree } \\
\hline & $\begin{array}{l}\text { Strongly } \\
\text { disagree }\end{array}$ & $\begin{array}{l}\text { Somewhat } \\
\text { disagree }\end{array}$ & $\begin{array}{l}\text { Neither agree } \\
\text { nor disagree }\end{array}$ & $\begin{array}{l}\text { Somewhat } \\
\text { agree }\end{array}$ & $\begin{array}{l}\text { Strongly } \\
\text { agree }\end{array}$ \\
\hline $\begin{array}{l}\text { 1. I was bored during classes } \\
\text { at secondary school. }\end{array}$ & 1 & 2 & 3 & 4 & 5 \\
\hline $\begin{array}{l}\text { 2. The teaching methods } \\
\text { used caused boredom } \\
\text { during classes. }\end{array}$ & 1 & 2 & 3 & 4 & 5 \\
\hline $\begin{array}{l}\text { 3. The quality of the learning } \\
\text { content caused boredom } \\
\text { during classes. }\end{array}$ & 1 & 2 & 3 & 4 & 5 \\
\hline $\begin{array}{l}\text { 4. The environment caused } \\
\text { boredom during classes. }\end{array}$ & 1 & 2 & 3 & 4 & 5 \\
\hline $\begin{array}{l}\text { 5. The teacher caused } \\
\text { boredom during classes. }\end{array}$ & 1 & 2 & 3 & 4 & 5 \\
\hline
\end{tabular}

The questions were designed in a way that would accommodate UoT students who are instructed in the medium of English as a second language. 


\section{Analysis of results}

It consisted of 82.7 per cent of first-year students between 18 and 27 years of age; and 15.6 per cent of students 28 years of age and above; and 1.7 per cent unusable In terms of gender distribution, the sample comprised 58.1 percent male students and 40.2 per cent female students (with $1.7 \%$ of the questionnaires incomplete). The various language groups were recoded to two, as African home languages were dominant: 63.1 per cent were African students; 35.2 per cent were grouped as "other" (all languages not specified in Section A) = and 1.7 per cent unusable.

With regard to perceived competency of spoken English, the original four groups were recoded to two, as there were too few students in the "poor" and "very good competency" categories. Half (50.8\%) rated their own spoken English as "poor to average", and 48.6 per cent rated it as "good to very good" = and 0.6 per cent unusable. About one-third rated their selfperceived written English as "poor to average" and as much as 62.6 per cent as "good to very good", and 1.1 per cent unusable.

Furthermore, the largest proportion $(38.5 \%)$ of the students had attended township secondary schools and about one-third (30.2\%) had attended rural secondary schools, both categories of which tend to be under-resourced; less than one-third (30.7\%) had attended the better resourced ex-model $\mathrm{C}$ secondary schools (information about $0.6 \%$ of the sample was unusable).

\section{Data analysis}

Factor analysis was used to determine the factors present in the causes of boredom in the classroom. Descriptive statistics analysis was employed for the data available. Conclusions were drawn from the student responses of those who participated in the survey and the Statistic Package for Social Scientists (SPSS 24.0) and STATISTICA were used to process the raw data.

\section{RESULTS AND DISCUSSION}

The primary objective of this study was to establish the level of boredom of students at secondary school and tertiary education level, so the questionnaire contained similar items for both. For convenience, we first discuss the factor analytic procedure of the data in respect of secondary schools.

\section{Secondary schools}

A factor analytic procedure (PCA with Varimax rotation) of the 38 items in section B of the 
questionnaire was applied, to establish the number of factors relevant to the construct of boredom at secondary schools. The measure of sampling adequacy (MSA) of some of the items were below the recommended acceptable value of 0.6 (Norusis 2009, 324; Field 2009, 647) and were thus excluded from the factor analysis. The Kaiser-Meyer-Olkin (KMO) test, which measures the suitability of data for factor analysis, of the remaining 32 items increased to 0.728 . The 11 first-order factors that remained could explain 67.4 per cent of the variance present. These factors with their items were:

- $\quad$ FB1.1 Bias towards educational context (B23, B22, B24, B21, B20)

- $\quad$ FB1.2 Factors that caused boredom during class (B3, B5, B2, B1)

- $\quad$ FB1.3 Coping mechanisms when bored during class (B30, B29, B31, B32)

- $\quad$ FB1.4 Quality of learning content (RB14, RB16, RB17)

- $\quad$ FB1.5 Time-frame of boredom during class (B25, B26, B28)

- $\quad$ FB1.6 Coping mechanisms using technology (B34, B37, B35)

- $\quad$ FB1.7 Manageability of learning content (RB18, RB19)

- $\quad$ FB1.8 Barriers that caused boredom (B13, B8, B12, B11)

- $\quad$ FB1.9 Importance of learning material (B6)

- $\quad$ FB1.10 Dealing with boredom (B15, B36)

- FB1.11 Preference for more important activities as coping mechanisms (B38, B9)

As 11 first-order factors were still too many, a second-order procedure was conducted still using PCA with Varimax rotation. Three second-order factors resulted, which explained 51.43 per cent of the variance present. The second-order factors and their first-order factors were as follows:

- $\quad$ FB2.1 Coping mechanisms (FB1.6 + FB1.3 + FB1.2 + FB1.10) $($ Cronbach $=0.778$ 13 items)

- $\quad$ FB2.2 Internal and external barriers causing boredom (FB1.8 + FB1.1 + FB1.11 + FB1.9) $($ Cronbach $=0.75210$ items $)$

- $\quad$ FB2.3 Content of learning material and time-frame of boredom (FB1.7 + FB1.4 + FB1.5) $($ Cronbach $=0.260)$. On removal of first-order factor FB1.5 the Cronbach increased to a more acceptable 0.756 for 5 items). Thus FB2.3 was taken as being composed of FB1.7 + FB1.4 (all items had their scale reversed).

When these three second-order factors (FB2.1, FB2.2 and FB2.3) were again subjected to a 
third-order analysis, only one factor resulted which was named "Aspects influencing boredom at secondary level of the educational system" (FB3.0). It had a Cronbach reliability coefficient of 0.853 and contained 32 items. The data distribution is shown in the histogram and boxplot in Figure 1.
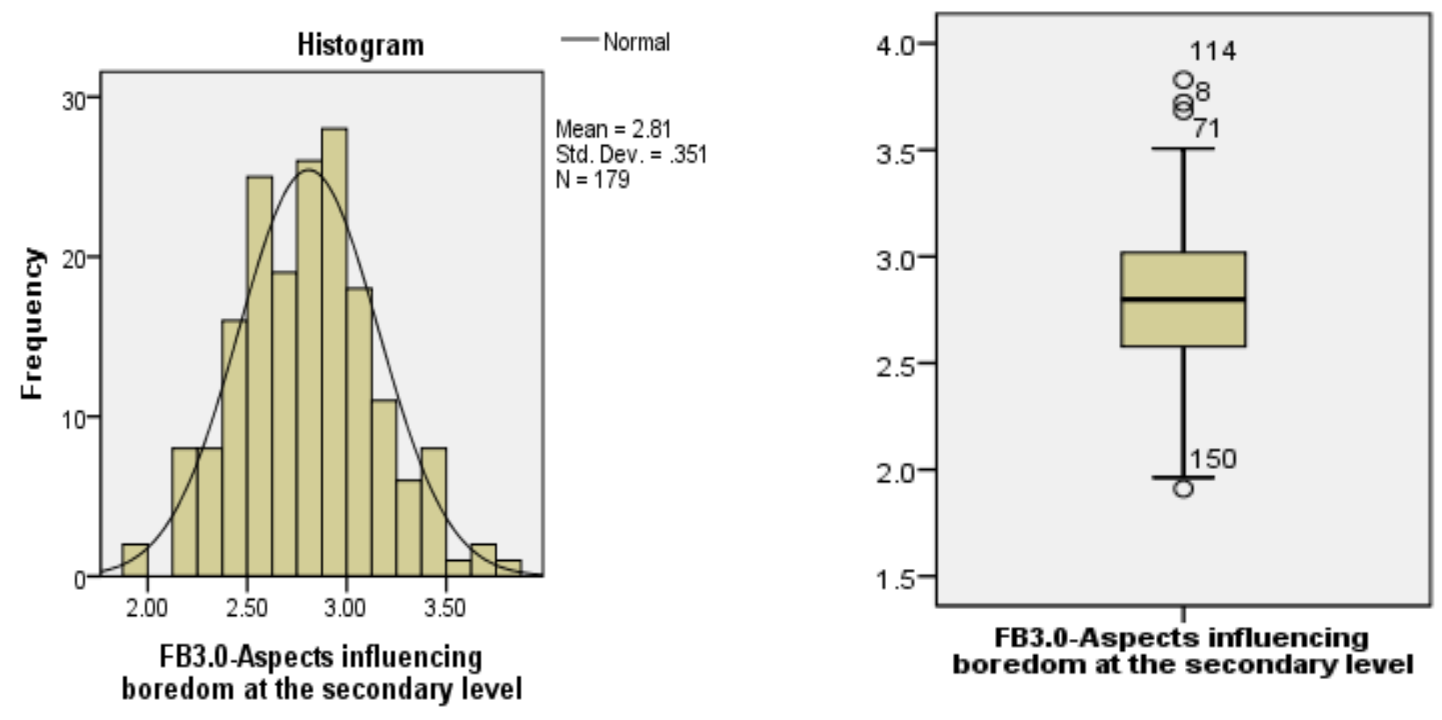

Figure 1: The data distribution of aspects influencing boredom at the secondary school level (FB3.0)

The mean of 2.81 with median of 2.80 are both shown in Figure 1. A few outliers were also present but these were not removed. The Kolmogorov-Smirnov test had a $p$ value $>0.05$, indicating that the distribution in the sample was not significantly different from a normal distribution (Field 2009, 144). Furthermore, when bootstrapping was applied no difference in the mean score was noticed for 1000 repeated samples, hence the sample mean is a good estimate of the population mean (Field 2016, 701).

The mean score of 2.8 on the 5-point Likert scale suggests that the respondents felt neutral about the level of boredom they had experienced at secondary school, which indicates that they perceived themselves as not having been bored during their secondary school experience.

\section{Tertiary education level}

There were 44 items that probed the perceptions of the respondents in the sample as to their experience of boredom at the tertiary education level. They had to provide an answer on a 5point Likert scale, where 1 represented "strongly disagree" that they were bored and 5 represented "strongly agree" that they were bored. The 44 items were again subjected to a factor analytic procedure in an effort to see if items would not group together and so provide a more parsimonious number of factors to work with. The initial KMO value of 0.775 and Bartlett's 
sphericity of $p=0.000$ indicated that such a procedure would be feasible. The Bartlett test was conducted to calculate an independent samples t-test (O'Reilly 2012, 167). This test was conducted to obtain factors that initiated and indicated the level of boredom during class at tertiary education level. However, items B13, 15, 19, 39, 40, 41, 42 and 44 all had KMO values smaller than the suggested 0.60 and were removed one at a time. The KMO value increased to a more acceptable 0.822 while the Bartlett's sphericity remained at $p=0.000$. There were 10 first-order factors that explained 69.17 per cent of the variance present. These factors with their items were:

- $\quad$ FC1.1 Educational environment (C2, C1, C3, C5, C28)

- $\quad$ FC1.2 Bias towards educational context (C22, C23, C21, C24)

- $\quad$ FC1.3 Coping mechanisms when bored during class $(\mathrm{C} 29, \mathrm{C} 30, \mathrm{C} 31, \mathrm{C} 32, \mathrm{C} 12$, C6)

- $\quad$ FC1.4 Coping mechanisms using technology (C37, C34, C36, C38)

- FC1.5 Quality of learning content $(\mathrm{C} 18, \mathrm{C} 16, \mathrm{C} 17, \mathrm{C} 14, \mathrm{C} 20)$

- $\quad$ FC1.6 Internal and external barriers to boredom $(\mathrm{C} 8, \mathrm{C} 7, \mathrm{C} 9)$

- $\quad$ FC1.7 Language proficiency and learning content $(\mathrm{C} 16, \mathrm{C} 11)$

- $\quad$ FC1.8 Time frame during which boredom occurred (C27, C26, C25)

- $\quad$ FC1.9 Coping mechanisms when bored during class (C39, C35, C43, C33)

- $\quad \mathrm{FC} 1.10$ Environmental influence (C4)

A second-order procedure on the 10 first-order factors, again using PCA and Varimax rotation, resulted in three second-order factors that explained 64.61 per cent of the variance present. These three factors were:

- $\quad \mathrm{FC} 2.1(\mathrm{FC} 1.1+\mathrm{FC} 1.3+\mathrm{FC} 1.8+\mathrm{FC} 1.4+\mathrm{FC} 1.7+\mathrm{FC} 1.10+\mathrm{FC} 1.2)(\mathrm{Cronbach}=$ $0.906)$

- $\quad$ FC2.2 $\mathrm{FC} 1.5+\mathrm{FC} 1.6($ Cronbach $=0.582)$

- $\quad$ FC2.3 FC1.9 $($ Cronbach $=0.590)$

A third-order procedure resulted in one factor only, consisting of 37 items, and it was named "Aspects influencing boredom at tertiary level (FC3.0)". This factor contained 36 items, and had a Cronbach reliability coefficient of 0.877 , and explained 50.73 per cent of the variance present. The data distribution of this factor is shown in the histogram and boxplot in Figure 2 . 

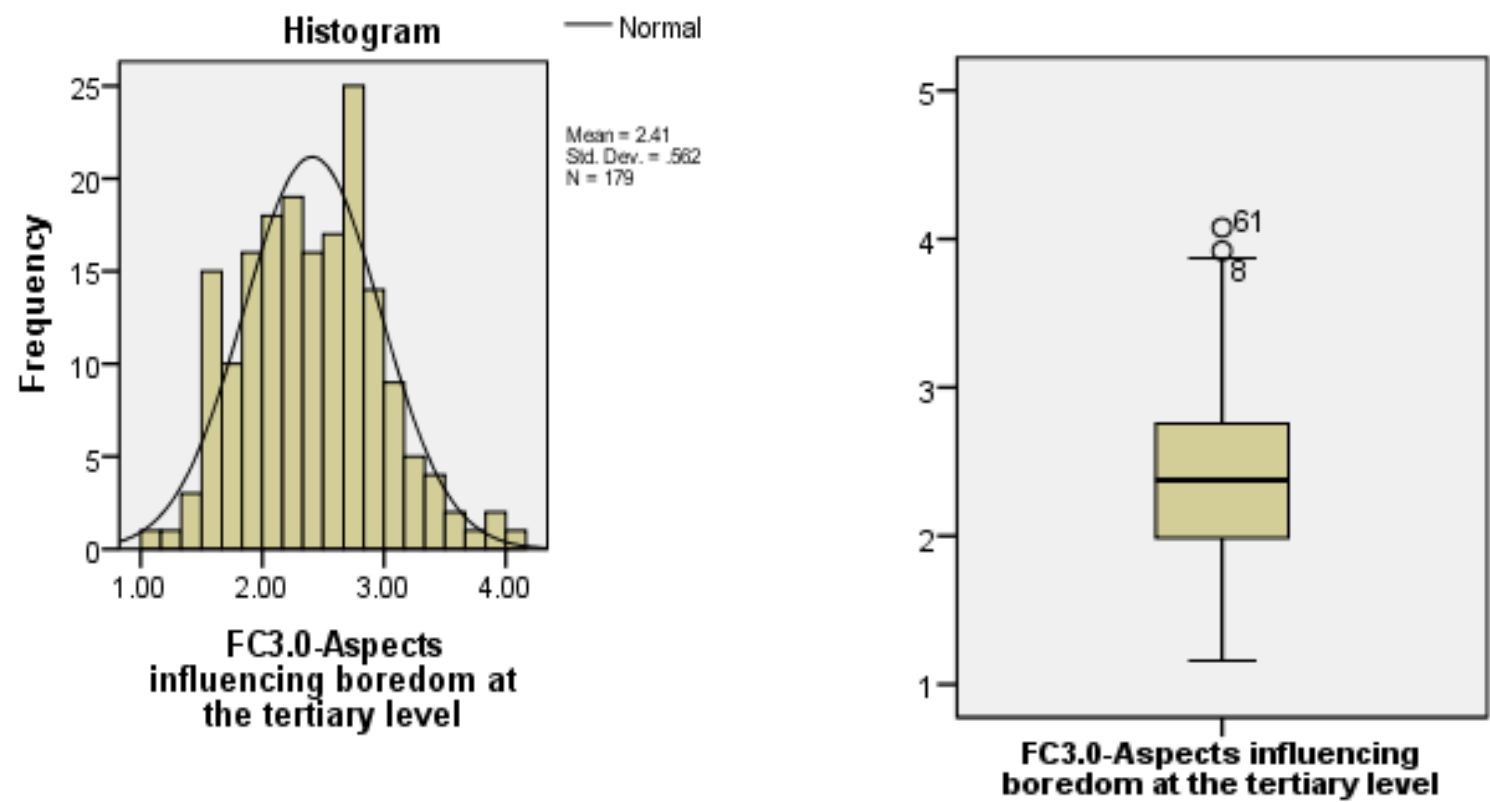

Figure 2: The data distribution of the items in the factor aspects influencing boredom at the tertiary education level

The mean of 2.41 with median of 2.38 are both shown in Figure 2. There were also two outliers present, but they were not removed. The Kolmogorov-Smirnov test had a $p$ value $>0.05$ indicating that the distribution in the sample was not significantly different from a normal distribution (Field 2009, 144). Furthermore, when bootstrapping was applied no difference in the mean score was noticed for 1000 repeated samples, hence the sample mean is a good estimate of the population mean (Field 2016, 701).

With a mean of 2.41, the respondents seemed to tend towards disagreeing somewhat with the items in the factor. This implies that, at the tertiary education level, the students in the sample did not seem to have a problem with being bored.

A further test was conducted to establish which factors were responsible for the difference of the boredom level at secondary school and tertiary education level. As the same students completed the questionnaire, the mean scores of both factors FB3.0 (second order factors FB2.1, FB2.2 and FB2.3, as explained in the second- and third-order factor analysis, fig.1) and FC3.0 (second-order factors FC2.1, FC2.2 and FC2.3, as explained in the second- and thirdorder analysis, fig.2) can be compared using the paired samples t-test (Field 2009, 325). The results of this test are given in Table 2 .

It can be concluded that the students' perceptions of boredom at tertiary education level were statistically significantly lower than they had been at secondary school level. Moreover, the effect size was large, so the effect is substantive or important. To see where the actual 
Table 2: The paired samples test for the two boredom factors (FB3.0 and FC3.0)

\begin{tabular}{|l|l|l|l|l|l|}
\hline Pair 1 & Group & Mean & t-test & p-value & Effect size \\
\hline FB3.0-FC3.0 & Secondary & 2.81 & $\begin{array}{l}10.894 \\
(178 \mathrm{df})\end{array}$ & $0.000^{* *}$ & 0.63 \\
\cline { 2 - 3 } & Tertiary & 2.41 & & \\
\hline
\end{tabular}

${ }^{* *}=$ Statistically significant at the 1 per cent level $(p<0.0005)$

Effect size $=r=0.10$ to $0.29=$ small; 0.30 to $0.49=$ moderate; $0.50+=$ large

differences lie, one can now attempt to see which of the paired items (B and C) were most likely to contribute towards the factor mean differences. It is convenient to arrange these pair-wise differences according to effect size as this is a standardized measure that makes direct comparisons possible.

Some of the more important pair-wise comparisons are given in Table 3.

Table 3: The paired boredom items arranged according to effect size

\begin{tabular}{|l|l|l|l|}
\multicolumn{1}{|c|}{ Paired items } & \multicolumn{1}{|c|}{$\begin{array}{c}\text { Effect } \\
\text { size }\end{array}$} & \multicolumn{1}{|c|}{$\begin{array}{c}\text { Mean } \\
\text { difference }\end{array}$} & \multicolumn{1}{|c|}{$\begin{array}{c}\text { Level more } \\
\text { likely to be } \\
\text { bored }\end{array}$} \\
\hline $\begin{array}{l}\text { C33 \& B33. I talk to the person next to me when I am bored } \\
\text { during classes }\end{array}$ & 0.49 & Negative & \multicolumn{1}{|c|}{ Secondary } \\
\hline $\begin{array}{l}\text { C32 \& B32. I scribble e.g. on hand-outs when I am bored } \\
\text { during classes }\end{array}$ & 0.34 & Negative & Secondary \\
\hline C36 \& B36. I leave the class prematurely when I am bored & 0.24 & Positive & Tertiary \\
\hline $\begin{array}{l}\text { C35 \& B35. I write notes to friends when I am bored during } \\
\text { classes }\end{array}$ & 0.23 & Negative & Secondary \\
\hline $\begin{array}{l}\text { C24 \& B24. I am biased towards the theme of the learning } \\
\text { content during classes }\end{array}$ & 0.20 & Negative & Secondary \\
\hline $\begin{array}{l}\text { C23 \& B23. I was biased towards the subject content during } \\
\text { classes }\end{array}$ & 0.19 & Negative & Secondary \\
\hline C30 \& B30. I doodled when I was bored during classes & 0.18 & Negative & Secondary \\
\hline C20 \& B20. I find the learning content difficult during classes & 0.17 & Positive & Tertiary \\
\hline
\end{tabular}

Effect size $=r=0.10$ to $0.29=$ small; 0.30 to $0.49=$ moderate; $0.50=$ large

$\mathrm{C}>\mathrm{B}$ equates to higher score on scale of $\mathrm{C}$ than $\mathrm{B}$ giving a positive difference because respondents agreed more strongly with the $C$ item than the $B$ item

$\mathrm{C}<\mathrm{B}$ equates to lower score on scale of $\mathrm{C}$ than $\mathrm{B}$ giving a negative difference because respondents agreed less strongly with the $C$ item than the $B$ item.

The data in Table 3 indicate that in most cases the particular behaviour was agreed to more strongly at secondary level than at tertiary level and, by implication, was more likely to occur at the secondary than at the tertiary level. The exceptions were items C36 and B36 ("I left the classes prematurely when I was bored during classes") and C20 and B20 ("I found the learning content more difficult"). The leaving of classes prematurely is probably due to the greater freedom associated with tertiary education and possibly the acceptance of personal responsibility for academic achievement. Finding the learning content more difficult at tertiary level seems to be logical, as the learning content is more advanced and there are large content areas that need to be covered. Greater personal responsibility is thus placed upon the individual 
student with respect to academic achievement.

A further objective was to test the various factors as dependent variables against the independent variables so as to determine possible associations between them.

\section{Testing for associations with the independent groups in the sample}

Levene's t-test is commonly used when testing for the differences in the mean scores of two independent groups. This test first investigates the variances between the mean scores of two independent groups (for example, male and female respondents) and, should equal variances be present (as indicated by the F value with $p$-value either greater than $p=0.05$ or less than 0.05 ), one either assumes equal variances or one does not assume equal variances. The data for this test is shown in Table 4.

Table 4: Differences between the mean scores of the two gender groups with respect to the two boredom factors FB3.0 and FC3.0

\begin{tabular}{|l|c|c|c|c|}
\hline \multicolumn{1}{|c|}{ Factor } & Group & $\begin{array}{c}\text { Mean } \\
\text { score }\end{array}$ & $\begin{array}{c}\text { t-test } \\
(\mathbf{p} \text {-value) }\end{array}$ & $\begin{array}{c}\text { Effect } \\
\text { size (r) }\end{array}$ \\
\hline \multirow{2}{*}{ Boredom at secondary level } & Male & 2.78 & \multirow{2}{*}{0.362} & \multirow{2}{*}{0.07} \\
\cline { 2 - 3 } & Female & 2.83 & \multirow{2}{*}{$0.031^{*}$} & \multirow{2}{*}{0.16} \\
\hline \multirow{2}{*}{ Boredom at tertiary level } & Male & 2.33 & \\
\cline { 2 - 3 } & Female & 2.51 & \\
\hline
\end{tabular}

${ }^{*}=$ Statistically significantly different at the 5 per cent level $(p<0.05)$

The data in Table 4 indicate that male and female respondents differed statistically significantly from one another only with respect to boredom at the tertiary education level (FC3.0). Although both gender groups showed some degree of boredom at the tertiary level, female students experienced a higher degree of boredom than their male counterparts. It is possible in the South African context that female students are less career orientated than male students and thus experience a higher degree of boredom than male students. This could be a useful area for future research

Furthermore, according to Lowder (2012), "black women in South Africa are likely to be both primary caregivers and primary breadwinners in our families", which could suggest that female students may have the added chore of organizing food availability as part of their normal household duties and, for example, may be more likely to write shopping lists than male students

To test this premise, we tested Item B38 (writing of shopping lists when bored) against gender, using both the non-parametric Mann-Whitney U-test and the independent t-test; in both instances female respondents had the highest mean score, which differed statistically 
significantly from that of the male respondents. The results of the t-test were:

$\left[\overline{\boldsymbol{X}}_{\text {Males }}=1.18 ; \overline{\boldsymbol{X}}_{\text {Females }}=1.45 ; \boldsymbol{p}=0.04 ; \boldsymbol{r}=0.19\right]$

\section{Differences between home language groups (A3Rec)}

As there were so few students in our sample who did not have an African language as home language, only two groups were formed for the purpose of testing. The summarised results were:

$\left[\boldsymbol{F C} 3.0 \bar{X}_{\text {African }}=2.37 ; \bar{X}_{\text {other }}=2.46 ; \boldsymbol{p}=0.208\right]$

$\left[\boldsymbol{F B} 3.0 \overline{\boldsymbol{X}}_{\text {African }}=2.78 ; \overline{\boldsymbol{X}}_{\text {other }}=2.85 ; \boldsymbol{p}=0.305\right]$

No statistically significant differences could be found on either boredom at secondary school or boredom at the tertiary education level with respect to home language. However, we found that at both secondary and tertiary levels the respondents who had an African home language indicated that they were less bored than the other participants. This difference was not statistically significant and could thus be due to chance factors.

\section{Perceived level of spoken English (A4Rec)}

The original four groups in the questionnaire were collapsed into two groups, namely, "poor to average" and "good to very good". The abbreviated results obtained were:

$$
\begin{aligned}
& {\left[\boldsymbol{F B} 3.0 \overline{\boldsymbol{X}}_{\text {Poor } / A v}=2.82 ; \overline{\boldsymbol{X}}_{\text {Good } / V G}=2.78 ; \boldsymbol{p}=0.424\right]} \\
& {\left[\boldsymbol{F C 3 . 0} \overline{\boldsymbol{X}}_{\text {Poor } / A v}=2.39 ; \overline{\boldsymbol{X}}_{\text {Good } / V G}=2.42 ; \boldsymbol{p}=0.736\right]}
\end{aligned}
$$

These results show that the respondents who perceived their own spoken English language to be poor to average were prone to be bored to a lesser extent than respondents who perceived their spoken English to be good to very good. This was the case for both secondary school and tertiary education levels. It may be that students who felt that their spoken language proficiency was poor were more motivated to pay attention in order to be able to understand the learning material presented. A sympathetic approach by the lecturers to accommodate learners by doing their best to make the material as accessible as possible may have contributed to less boredom among the learners with self-perceived low spoken language proficiency. 
This interpretation is supported by Weimer (2014) who proposed that teachers should try to improve student attentiveness by using a variety of instructional approaches, especially those that actively engage students. Such activities enable students to encounter the content in different formats and make it easier for them to pay attention after the activity has ended.

However, these differences were not statistically significant, so one cannot rule out chance factors and this event cannot be inferred to the population. This offers an opportunity for further research.

\section{Secondary school attended (A6)}

The original four groups were left unchanged and, as there were three independent groups, we could use ANOVA to test for any significant differences between the three groups taken together. The results were:

$$
\begin{aligned}
& {\left[F B 3.0 \bar{X}_{\text {Towns }}=2.87 ; \bar{X}_{M C / \text { Town }}=2.77 ; \bar{X}_{M C / R}=2.74 ; \bar{X}_{R}=2.77 ; F(3,174)=1.245 ; p=0.295\right]} \\
& {\left[F C 3.0 \bar{X}_{\text {Towns }}=2.46 ; \bar{X}_{M C / \text { Town }}=2.47 ; \bar{X}_{M C / R}=2.44 ; \bar{X}_{R}=2.28 ; \boldsymbol{F}(3,174)=1.375 ; p=0.252\right]}
\end{aligned}
$$

The data indicate no statistically significant associations among the three groups. However, one could say that in this sample of respondents, students who attended both rural and ex-model C schools perceived themselves as being less bored than those students who had attended township schools at both secondary and tertiary levels.

The actual symbols attained by students in English Second Language (spoken and written) in the National Senior Certificate examination (NSC) could, unfortunately, not be obtained, which limits the extent to which conclusions could be drawn from our results at this UoT. This leaves scope for further investigation into the effects of language proficiency on boredom in the tertiary level classroom.

From the results and discussion, the following implications should be considered for higher education. Due to the diversity of this institution's learners, it is of utmost importance that there is harmony between culture, training, pedagogy and classroom context. It is therefore important to make certain that the learning content is accessible. Therefore, learning content and teaching methods should be revisited from time to time to address this diversity.

Secondly, practitioners should know their students and ensure that every student is engaged, challenged and learning successfully. This might be achieved by incorporating technology to assist the teaching process, such as videos on YouTube; digital resources to engage students; interactive games which involve students with the learning concepts and group 
work which necessitates participation.

A third implication may be that due to the vastly differing backgrounds of South African students and job creation among the youth, it is of great importance to focus subject content with these factors in mind. The usefulness of social media and its popularity among the youth is a facet which should be more effectively utilised. For example, students could be given a research project where they have to make use of social media to investigate the role of small and medium enterprises in job creation in rural areas. Thus, the subject content is given deeper meaning as it is related to something they come into contact with on a daily basis. It will also expose the students to aspects of community service and how these impacts on the daily lives of their communities.

\section{CONCLUSION}

In this study, where the boredom factor was evaluated against the learning content and teaching methods, the results unexpectedly indicated that the boredom levels of the students in our sample of first-year UoT students in the Applied Communication Skills class were significantly lower than had been anticipated.

This study points to further avenues through which to investigate student boredom in both the secondary and tertiary classroom, for example students' language proficiency. The statistically significant variations that we noted could point to aspects of teaching and learning on which to focus when designing curricula and pedagogical improvements. Furthermore, the results suggest further opportunities for more detailed research into, for example, possible reasons why the female students appeared to experience greater levels of boredom in the higher education classroom than their male counterparts.

In light of the findings, the researchers recommend that the quality of the teaching methods and learning material as contributing factors to the experience of boredom, have to receive much attention on all educational levels. The importance hereof is substantiated in a study by Livingstone (2015) which suggests an inverse correlation between factors such as the learning content and the manifestation of boredom.

Improving the learning content and its pedagogical means should decrease feelings of boredom in the learning environment. This study showed the importance of striving to promote the pedagogical principles of learning and teaching. It also complies with the objectives of the White Paper for Post-School Education and Training where encouraging different modes of teaching, learning and assessment are advocated (White Paper for Post-School Education and Training 2013, 45). It is thus recommended that practitioners strive to achieve success in the classroom, by: 
- $\quad$ compiling interesting learning material in order to engage students and ensure focus and positive interaction;

- taking the level of students' comprehension in consideration when designing study material;

- $\quad$ displaying a sympathetic approach towards English second language learners as well as English foreign language speakers in the classroom, as their levels of language proficiency may differ; and

- $\quad$ considering the divergent educational background of learners.

Students who exhibit symptoms of boredom should be identified as early as possible, and referred to the Students Counselling and Support Department of this institution.

To conclude it is advisable to establish the boredom levels of students on a regular basis to establish if learning content and teaching methods are on standard. Lecturers must be aware that they are only effective to the extent that they can transfer their know-how in the local context, and to the extent that their proposed suggestions fit in with the needs and priorities of the receiving students. This demands intercultural understanding and effective communication skills.

\section{REFERENCES}

Amos, A., S. Wiltshire, S. Haw and A. McNeill. 2006. Ambivalence and uncertainty: Experiences of and attitudes toward addiction and smoking cessation in the mid-to-late teens. Health Education Research 21: 181-191.

Berlyne, D. E. 1960.Conflict, arousal and curiosity. New York: McGraw-Hill.

David, L. 2018. Constructivism in Learning Theories. http://www.teach-nology.com/currenttrends/ constructivism/piaget/ (Accessed 21 May 2018).

Eastwood, J. D., A. Frischen, M. J. Fenske and D. Smilek. 2012. The unengaged mind: Defining boredom in terms of attention. Perspectives on Psychology Science 7: 482-495 .

Eastwood, J. 2013. http://www.boredomlab.org/msbs (Accessed 12 March 2017).

Fahlman, S. A., K. B. Mercer, P. Gaskovski, A. E. Eastwood and J. D. Eastwood. 2009. Does a lack of life meaning cause boredom? Results from psychometric, longitudinal, and experimental analyses. Journal of Social and Clinical Psychology 28: 307-340.

Fallis, R. and S. Optotow. 2003. Are students failing schools or are schools failing students? Class cutting in high school. Journal of Social Issues 59(1): 103-119.

Farmer, F. and N. D. Sundberg. 1986. http://www.leaonline.com/doi/abs/10.1207/s15327752jpa5001 2?journalCode=jpa (Accessed 12 March 2017).

Field, A. 2009. Discovering statistics using SPSS. $3^{\text {rd }}$ Edition. Sage Publications Ltd., London.

Field, A. 2016. An adventure in statistics: The reality enigma. University of Sussex, UK.

Fisher, C. D. 1993. Boredom at work: A neglected concept. Human Relations 46: 395-417. 
Frankl, V. 1984. Man's search for meaning: An introduction to logotheraphy. New York: Pocket Books.

Fraser, W. and R. Killen. 2005. The perceptions of students and lecturers of some factors influencing academic performance at two South African universities. Perspectives in Education 23(1): 25-29

Geiwitz, P. J. 1996. Structure of boredom. Journal of Personality and Social Psychology 3: 592-600.

Goldberg, Y. K., J. D. Eastwood, J. LaGuardia and J. Danckert. 2011. Boredom: An emotional experience distinct from apathy, anhedonia, or depression. Journal of Social and Clinical Psychology 30: 647-666.

Greenson, R. R. 1953. On boredom. Journal of American Psychoanalitic Association 1: 7-21.

Hamilton, J. 1981. Attention, personality, and self-regulation of mood: Absorbing interest and boredom. Progress in Experimental Personality Research 10: 281-315.

Hamilton, J. A., R. J. Haier and M. S. Buchsbaum. 1984. Intrinsic enjoyment and boredom coping scales: Validation with personality, evoked potential, and attention measures. Personality and Individual Differences 5: 183-193.

Harris, M. 2000. Correlates and characteristics of boredom proneness and boredom. Journal of Applied Social Psychology 30: 576-598.

Hebb, D.1966. A textbook of psychology. Philadelphia, PA: W.B. Saunders.

Hill, A. B. and R. E. Perkins. 1985. Towards a model of boredom. British Journal of Psychology 76: 235-240.

Livingstone, S. 2015. Causes and cures for classroom boredom - Learning liftoff. https://www. learningliftoff.com/causes-and-cures-for-classroom-boredom (Accessed 24 May 2018).

Lowder, J. B. 2012. http://www.slate.com/bloggs/xx_factor/2012/04/05women_as_breadwinner_blade _women_fill_role_in_family (Accessed 25 January 2018).

Lipps, T. 1903. Leitfaden der Psychologie [Manual of psychology]. Leipzig, Germany: Wilhelm Engelman Verlag.

Macklem, G. L. 2015. Boredom in the classroom: Addressing student motivation, self-regulation, and engagement in learning. New York: Springer.

Mann, S. and A. Robinson. 2009. Boredom in the lecture theatre: An investigation into the contributors, moderators, and outcomes of boredom amongst university students. British Educational Research Journal 35(2): 243-258.

Melton, A. M. and S. E. Schulenberg. 2007. On the relationship between meaning in life and boredom proneness: Examining a logotherapy postulate. Psychological Reports 101: 1016-1022.

Norusis, M. J. 2009. SPSS Statistics 17.0: Guide to Data Analysis: 324.

O'Hanlon, J. F. 1981. Boredom: Practical consequences and a theory. Acta Psychologica 49: 53-82.

O'Reilly, M. 2012. Big data now: Current perspectives from O'Reilly Media. 2012 Edition. O'Reilly Media, Inc.: UK.

Piaget, J. 1936. Origins of intelligence in the child. London: Routledge \& Kegan Paul.

Pekrun, R., T. Goetz, L. M. Daniels, R. H. Stupnisky and R. P. Perry. 2010. Boredom in achievement settings: Control value and antecedents and performance outcomes of a neglected emotion. Journal of Educational Psychology 102: 531-549.

Pekrun, R., T. Goetz, N. C. Hall and R. P. Perry. 2014. Boredom and academic achievement: Testing a model of reciprocal causation. Journal of Educational Psychology 106(3): 696-710.

Siniscalco, M. T. and N. Auriat. 2005. Quantitative research methods in educational planning. Module 8. International Institute for Educational Planning / UNESCO. http://www.unesco.org.iiep (Accessed 21 May 2018).

Todman, M. 2003. Boredom and psychotic disorders: Cognitive and motivational issues. Psychiatry 66: $146-147$.

Tze, V. M. C., L. M. Daniels, R. N. Klassen and J. C.-H. Li. 2013. Canadian and Chinese university 
students' approaches to coping with academic boredom. Learning and Individual Differences 23: $32-43$

UNESCO. 2018. BRIEF 3: Learning and teaching materials.

Van Tilburg, W. A. P. and E. R. Igou. 2011. On boredom: Lack of challenge and meaning as distinct boredom experiences. Motivation and Emotion. Advance online publication. Doi:10.1007/s11031 $-011-9234-9$

Van Tilburg, W. A. P. and E. R. Igou. 2012. On boredom: Lack of challenge and meaning as distinct boredom experiences. Motivation and Emotion 36: 181-194. Doi:10.1007/s11031-011-9234-9.

Vogel-Walcutt, J. J., L. Fiorella, T. Carper and S. Schatz. 2012. The definition, assessment, and mitigation of state boredom within educational settings: A comprehensive review. Educational Psychology Review 24: 89-111.

Ward, T. 2003. "I watched in dumb horror". The Guardian May 20.

Wegner, L., A. J. Fleischer, P. Chikobvu, C. Lombard and G. King. 2008. Leisure boredom and high school dropout in Cape town, South Africa. Journal of Adolescence 31(3): 421-431. doi:10.1016/j.adolescence.2007.09.004.

Weimer, M. 2014. Students and attention: An interesting analysis. 2018 Faculty Focus.

Weybright, E. H., L. L. Caldwell, N. Ram, E. A. Smith and S. Wegner. 2015. Boredom prone or nothing to do? Distinguishing between state and trait leisure boredom and its association with substance use in South African adolescents. Leisure Sciences 37(4): 311-331.

White Paper for Post-School Education and Training. 2013. Building an expanded, effective and integrated post-school system white paper for post-school education and training. As approved by Cabinet on 20 November 2013. Department: Higher Education and Training. 